\title{
WELL-BEHAVED PRODUCTION ECONOMIES
}

\author{
Michael Mandler \\ Royal Holloway College, University of London \\ (January 2004; revised July 2005)
}

\begin{abstract}
We show that production economies are tâtonnement stable if consumers satisfy the weak axiom of revealed preference. To ensure that producer supply decisions are well defined, we restrict prices in the tâtonnement so that positive profits cannot occur but do allow supply decisions to be multi-valued. The model therefore permits linear activities and hence the technologies that admit capital theory paradoxes. The result thus shows that if the consumer side of the economy is well behaved then capital theory paradoxes are irrelevant for stability. Other features of the Walrasian general-equilibrium model that have aroused suspicion (e.g. that a price below its equilibrium value may have negative excess demand and thus temporarily move even lower in a tâtonnement) may be a sign of trouble but also have nothing to do with capital theory paradoxes. We show that these phenomena arise even when there is no choice of technique and there is an aggregate production function.
\end{abstract}

\section{INTRODUCTION}

If the consumer side of a general-equilibrium model is sufficiently well behaved - say it satisfies the weak axiom of revealed preference - then only one aggregate demand vector can occur in equilibrium. If furthermore consumer demand behaves as if there were a single consumer with a differentiable utility function, then relative prices for consumption goods are uniquely determined, and if the utility function is concave, then the marginal value of every resource will be diminishing in its quantity. Hence, as I argued in Mandler (2002b), capital theory paradoxes will not by themselves lead to implausible comparative statics or multiple equilibria. For capital goods to be a source of trouble, they must somehow amplify the consequences of consumer behavior that is already less than well behaved, and this dependence makes it hard to attribute any problems to capital alone. Since Mandler (2002b) mentioned tâtonnement stability only in a phrase, I will take this chance to show that any production economy with well-behaved consumer demand is in addition tâtonnement stable, a result that both Garegnani $(2000,2005)$ and Schefold $(2000,2005 a)$ cast doubt on. 
We restrict producer prices along the tâtonnement so that production activities do not make positive profits, thus ensuring that each producer's profitmaximization problem has some solution. Tâtonnement stability then obtains whether production is atemporal or intertemporal and whether there are intermediate produced inputs. Once again, capital theory paradoxes are irrelevant.

The absence in the existing literature of well-specified tâtonnements for constant-returns production economies is no doubt to blame for the present controversy regarding the stability of equilibrium. More surprising is any continuing disagreement about the multiplicity of equilibria (Garegnani, 2005 ) and the comparative statics of how factor prices respond to endowment changes (Schefold, 2005a). I argued in Mandler (2002b) that the equilibria that disturb Schefold incorporate simultaneous shifts of factor demand and factor supply and hence would not lead even the most orthodox neoclassical economist to predict the direction prices will change. I hope to forge some progress here by showing that the comparative statics that bother Schefold have nothing to do with reswitching and can arise even in a parable economy with a single concave production function. The same disconnect between capital theory cause and equilibrium effect also arises in the dispute over stability. Schefold seems to be unhappy with a tâtonnement in which a factor with a price below its equilibrium value has a negative excess demand, thus leading to a temporary pause in the price's upward movement. We will see that factor prices in the end do still converge to equilibrium. But even the short-run pause has nothing to do with reswitching and arises in models with no choice of technique and with an aggregate production function.

My difficulties with Garegnani's model of out-of-equilibrium adjustment remain. To see whether capital paradoxes can lead investment demand to behave so perversely that it blocks adjustment to equilibrium, Garegnani's model expresses disequilibrium only in discrepancies between savings and investment, which in turn guide the adjustment path of interest rates; investment demand then plays a pivotal role in moving the economy towards or away from equilibrium. But goods markets do not clear along the adjustment path Garegnani considers, and puzzlingly the prices of goods do not adjust in response. To further the hunt for common ground, I sketch a model in which only the savings-investment market does not clear.

Finally, I argue that the Sraffian criticism of neoclassical models in which relative prices do not converge through time or converge too slowly is misleading. When resource endowments, tastes or technology steadily shift through time, relative price convergence will be problematic for any theory of intertemporal development. The difficulties of neoclassical models on this

(C) Blackwell Publishing Ltd 2005 
point are transparent because they lay out an explicit dynamic path of production and consumption along which markets clear. Sraffian models in contrast enjoy the luxury of constant relative prices but they achieve this feat only by fiat: the models duck any mention of dynamic paths and hence whether markets clear or even whether allocations are feasible.

\section{STABILITY WITH THE WEAK AXIOM}

Let there be $n$ goods with prices given by $p \geq 0$ and let $z(p)$ be a continuous excess demand function for the $n$ goods that is homogeneous of degree 0 , satisfies Walras' law $(p \cdot z(p)=0$ for all $p$ ), and has an equilibrium $p$ (a $p$ with $z(p)=0)$. We say that $z$ satisfies the weak axiom if whenever $p^{\prime} \cdot z(p) \leq 0$ and $z(p) \neq z\left(p^{\prime}\right)$ then $p \cdot z\left(p^{\prime}\right)>0$. That is, if the excess demand $z(p)$ is affordable when prices equal $p^{\prime}$ but instead $z\left(p^{\prime}\right)$ is chosen (so $z\left(p^{\prime}\right)$ is 'revealed preferred' to $z(p))$, then $z\left(p^{\prime}\right)$ must be unaffordable when prices equal $p$ and $z(p)$ is chosen. If an economy consists of a single consumer with a utility function $u$ that generates a single-valued excess demand function $z$ then $z$ will satisfy the weak axiom. ${ }^{1}$

In pure exchange settings, a tâtonnement is given by the differential equations

$$
\dot{p}_{k}=\alpha_{k} z_{k}(p), k=1, \ldots, n
$$

where each $\alpha_{k}$ is strictly positive. Arrow et al. (1959) showed long ago that if $z$ satisfies the weak axiom, then $p(t)$ will converge to an equilibrium $p$.

When production is present, consumer excess demand is set against firm supply. If the economy's profit-maximizing firms choose to supply just one vector of outputs, say $y(p)$, at any $p$ then the Arrow et al. result readily generalizes: one sets $\dot{p}_{k}=\alpha_{k}\left(z_{k}(p)-y_{k}(p)\right)$ and confirms that the weak axiom holds for the function $z(p)-y(p)$. But there are two good reasons not to assume that supply decisions are single-valued. First, there may be no point in a firm's production set that maximizes profits, e.g. if there is constant returns to scale and positive profits can be earned at some $p$ by supplying some vector $y$ then

\footnotetext{
${ }^{1}$ Formally, suppose $p^{\prime} \cdot z(p) \leq 0, z(p) \neq z\left(p^{\prime}\right)$ and, in violation of the weak axiom, $p \cdot z\left(p^{\prime}\right) \leq 0$. Then the agent, who consumes $x=z(p)+e$ at $p$, where $e$ is the agent's endowment, can afford $x^{\prime}=z\left(p^{\prime}\right)+e$ at $p$. So utility maximization implies $u(x) \geq u\left(x^{\prime}\right)$. Similarly $p^{\prime} \cdot z(p) \leq 0$ implies $u\left(x^{\prime}\right) \geq u(x)$, and therefore $u(x)=u\left(x^{\prime}\right)$. The agent's utility-maximization problem therefore cannot generate a single solution at either $p$ or $p^{\prime}$, and so $z$ could not specify one vector of excess demands at each $p$.
} 
profits increase without bound as $y$ is scaled up. Second, even if we place an upper bound on each firm's production set and consequently there is some profit-maximizing supply decision, there may still be multiple supply decisions that maximize profits. For instance, with linear activities, then even at a $p$ where positive profits cannot be earned and even if we constrain firms to produce the output levels that consumers demand at $p$, there may still be multiple combinations of zero-profit activities that can produce those outputs (since isoquants are piecewise linear). Given the prominence of linear activities in discussions of capital theory, it would be best not to rule out multivalued supply decisions.

As we will see presently, the second problem can be addressed by letting $\dot{p}_{k}$ be proportional to the difference between $z_{k}(p)$ and some point in the set of quantities of good $k$ that firms are willing to supply at $p$. The first problem, that firm profits may be unbounded, is more troublesome. Truncating firms' production sets is one reasonable way to proceed. It would be enough to assume that as a firm produces at a larger scale it suffers a progressively greater firm-specific adjustment cost. This solution may be ad hoc, but it does not violate the principle that inputs should be exhaustively enumerated nor does it preclude reswitching (as I believe Schefold suggests), and it has the advantage that each good's price is governed by a similar rule.

Schefold (2005a) sticks to an assumption of literal constant returns to scale and instead restricts prices so that firms' supply decisions are always well defined. The adjustment process begins with the announcement of prices for the non-produced goods which in Schefold's model consist of labor in each period and the initial period's stock of material goods. Given these prices, firms then announce the minimum cost of producing each of the outputs, and output prices are set equal to these minima. Each firm's profitmaximization problem will then have some solution. That firms just declare their production costs rests uneasily with prices being set by the market and (like adjustment costs) is ad hoc, but in the absence of an ideal theory of price adjustment, we pursue this resolution. Informally, one may think of output prices responding very quickly to the possibility of unbounded profits.

To generalize and simplify somewhat, we begin with an arbitrary set of $m$ non-produced goods, which we call factors, some or all of which can be consumed as well. The factors can serve as inputs to a set of linear activities that produce $\ell$ consumption goods that despite their label can be used as inputs as well as consumed $(\ell+m=n)$. We assume, following Schefold, that each activity produces just one of these $\ell$ goods (no joint production). The activities are assembled as an activity matrix $A$ with $\ell+m$ rows. Given an announcement of non-negative factor prices, say $w \geq 0$, the minimum production costs

(C) Blackwell Publishing Ltd 2005 
for output will be denoted $p_{c}(w)$. The vector $p_{c}(w)$ is obtained by minimizing $p_{c}$ s.t. $\left(p_{c}, w\right)^{\prime} A \geq 0$; the no joint production assumption implies that this problem has a unique solution.

We now define a tâtonnement for $w$ and give a stability result. Since consumption prices are always set equal to $p_{c}(w)$, we can express the excess demand for consumption goods and factors as functions of $w$ alone: $z_{c}(w)$ and $z_{f}(w)$. We assume these functions are continuous and satisfy Walras' law, $p_{c}(w) \cdot z_{c}(w)+w \cdot z_{f}(w)=0$ for all $w$. Implicitly, the functions $z_{c}$ and $z_{f}$ are determined by utility-maximizing consumers. If there is just one consumer, he or she chooses excess demands for output and factors, $\left(z_{c}, z_{f}\right)$, to maximize utility subject to the budget constraint $p_{c}(w) \cdot z_{c}+w \cdot z_{f} \leq 0$.

So far, we have one half of the tâtonnement, the supply of factors. Determining the demand for factors by firms is a little trickier since, as we mentioned, there can be multiple minimum-cost factor combinations that produce the outputs $z_{c}(w)$. To address this problem, we use the factor demand correspondence $Y_{f}(w)=\left\{y_{f}: y_{f}\right.$ solves $\max \left(p_{c}(w), w\right) \cdot\left(z_{c}(w), y_{f}\right)$ s.t. $\left(z_{c}(w), y_{f}\right)=A x$ for some $x \geq 0$, and $\left.\left\|y_{f}\right\| \leq K\right\}$, where the constant $K$ is chosen large enough so that $\left\|z_{f}(w)\right\| \leq K$ for all $w$. Since firms can always earn 0 profits by setting the activity levels $x$ equal to 0 , and $p_{c}(w)$ is set so that firms cannot earn profits any greater than $0, Y_{f}(w)$ is well defined. With the current notation, an equilibrium is a $w$ such that $z_{f}(w) \in Y_{f}(w){ }^{2}$

The price adjustment speeds for the tâtonnement are given by $\alpha \gg 0$. A path for factor prices is a function $w(t)$ defined for $t \geq 0$ with $w(0) \geq 0$ that is absolutely continuous (hence differentiable at almost every $t$ ) such that when differentiable at $t$ there is a $y_{f} \in Y_{f}(w(t))$ such that

$$
\dot{w}(t)=\left[\alpha_{1}\left(z_{f 1}(w(t))-y_{f 1}\right), \ldots, \alpha_{k}\left(z_{f k}(w(t))-y_{f k}\right), \ldots, \alpha_{m}\left(z_{f m}(w(t))-y_{f m}\right)\right]
$$

If we define the excess demand correspondence for factors, $\xi(w)=\left\{z_{f}(w)-\right.$ $\left.y_{f}: y_{f} \in Y_{f}(w)\right\}$, we can re-express the adjustment rule for $w$ as the requirement that, for all $t$ where $w$ is differentiable, $\dot{w}(t)=\left(\ldots, \alpha_{k} \xi_{k}, \ldots\right)$ for some $\xi \in$ $\xi(w(t))$. To rule out negative prices, we also define an amended adjustment rule that prohibits a negative right-hand derivative for the price path of any factor $k$ when $w_{k}(t)=0$ (even if some or all excess demands in $\xi_{k}(w(t))$ are negative), thus ensuring that $w(t) \geq 0$ for all $t$. Viewing $\xi$ as a correspondence of $p$, $\xi$ is upper hemicontinuous and convex-valued; it follows that paths that meet

${ }^{2}$ This trick of reducing a general equilibrium economy to a simpler model of factor demand and supply has repeatedly proved fruitful, e.g. for the existence of equilibrium (Arrow and Starrett, 1973) and for determinacy (Mandler, 1999, chap. 2). 
these adjustment rules necessarily exist. ${ }^{3}$ We call this model of price adjustment a factor tâtonnement.

In a single-consumer economy, the excess demand for consumption goods and factors taken together will continue to satisfy the weak axiom: $p_{c}\left(w^{\prime}\right) \cdot z_{c}(w)+w^{\prime} \cdot z_{f}(w) \leq 0$ and $\left(z_{c}\left(w^{\prime}\right), z_{f}\left(w^{\prime}\right)\right) \neq\left(z_{c}(w), z_{f}(w)\right)$ imply $p_{c}(w) \cdot$ $z_{c}\left(w^{\prime}\right)+w \cdot z_{f}\left(w^{\prime}\right)>0$. Although this condition does not mean that the correspondence $\xi(w)$ itself satisfies the weak axiom, ${ }^{4}$ we nevertheless have the following stability result, proved in the appendix.

Theorem: If excess demand for consumption goods and factors taken together satisfies the weak axiom, then any path $w(t)$ beginning from any $w(0) \geq 0$ converges to an equilibrium $w$. The same conclusion holds for the amended adjustment rule.

Let me now turn to Schefold's assertion that reswitching can lead to tâtonnement instability in a single-agent economy. ${ }^{5}$ Each period $t$ of Schefold's model begins with a stock of labor and material inputs, which are transformed by linear activities into goods that are either consumed at $t$ or invested as capital for production at $t+1$. Since each activity makes only one of the produced goods, Schefold meets the assumptions of the factor tâtonnement model: the initial period's stocks of capital inputs and the labor that appears each period are not produced and therefore qualify as factors, and all remaining goods qualify as consumption goods. And most of Schefold's description of how prices adjust through time matches the factor tâtonnement model as well. Given arbitrary factor prices, the auctioneer calculates prices that minimize the costs of the consumption goods that appear each period. Then, given these consumption and factor prices, the single agent of Schefold's model announces his factor supply and consumption demand, and firms announce profit-maximizing factor demands that meet the consumption demand. Factor prices then move according to the difference between factor demand and supply. Except for Schefold's neglect of the fact that factor

\footnotetext{
${ }^{3}$ Apply Aubin and Cellina (1984, Theorem 2.1.4). For the amended rule, apply the same theorem to $\hat{\xi}$ defined as follows for $k=1, \ldots, m$. For $w \in R^{m}$, let $\hat{w}=\operatorname{argmin}\left\|w^{\prime}-w\right\|$ s.t. $w^{\prime} \in R_{+}^{m}$. If either $w \in R_{+}^{m}$ and $w_{k}>0$ or $\xi_{k}(\hat{w}) \subset R_{+}$, set $\hat{\xi}_{k}(w)=\xi_{k}(\hat{w})$. If $w \notin R_{+}^{m}$ and $\xi_{k}(\hat{w}) \cap$ $R_{-} \neq \varnothing$, set $\hat{\xi}_{k}(w)=\{0\}$. If $w \in R_{+}^{m}, w_{k}=0$, and $\xi_{k}(\hat{w}) \cap R_{-} \neq \varnothing$, set $\hat{\xi}_{k}(w)$ equal to the convex hull of $\xi_{k}(w) \cup\{0\}$. See Champsaur et al. (1977) for similar constructions.

${ }^{4}$ That is, $\xi \in \xi(w), \xi^{\prime} \in \xi\left(w^{\prime}\right), w^{\prime} \cdot \xi \leq 0, \xi \neq \xi^{\prime}$ and $w \cdot \xi^{\prime} \leq 0$ may simultaneously be satisfied.

${ }^{5}$ In answer to Schefold's (2005b) query, I do not know how much light tâtonnement models shed on real-world price adjustment. My present aim is only to show that capital theory paradoxes per se do not lead to instability in existing models of general equilibrium price adjustment.
} 
demand can be multi-valued, the factor tâtonnement model and one of Schefold's adjustment mechanisms (the 'recursive' approach) coincide.

Schefold's example of instability is difficult to follow, but his test for instability seems to be that at some vector of factor prices the supply of some subset of factors does not equal demand, and yet the difference between demand and supply for those factors moves their prices away from equilibrium. Specifically, Schefold sets the wage in each period equal to 0 and argues that, given the remaining factor prices, the supply of labor in each period will be greater than demand. A tâtonnement then would not call for pushing wages up. (That factor demand can be multi-valued does not arise in the example since Schefold considers factor prices at which just one activity per produced good is profit-maximizing.)

How can such single-agent examples be reconciled with our stability theorem for the factor tâtonnement model? If labor at each date has a 0 wage and yet the supply of all types of labor outstrips demand, the amended adjustment rule for the factor tâtonnement would maintain the 0 wages for labor, just as Schefold would. But Schefold does not track how the prices of the initial stocks of capital inputs respond to the disequilibrium. The markets for the initial stocks cannot be in equilibrium at the factor prices Schefold considers, and their prices will move so that the distance between the entire announced out-of-equilibrium price vector and the entire equilibrium price vector is steadily decreasing. ${ }^{6}$ When each wage is held at 0 , all of the motion towards equilibrium takes place in the capital input prices. Of course, since the adjustment path ultimately converges to equilibrium, the demand for labor must at some later point become larger than demand.

That some factor prices can move closer to equilibrium while others move away is no mystery. For example, suppose some factor $k$ is used only to produce a certain good $a$. If $k$ is cheap relative to its equilibrium price but the other factors need to make $a$ are expensive then the price of $a$ might be so high that demand for $a$ and hence the demand for $k$ is low. If this out-ofequilibrium demand for $k$ is less than the supply of $k$, the price for $k$ will continue to fall under a factor tâtonnement (or stay at 0 ) despite $k$ 's low price.

Even if this behavior of a factor tâtonnement should be deemed troublesome, it is unrelated to reswitching or any other paradox of capital theory. This is difficult to see in Schefold's discussion, but notice that his more

\footnotetext{
${ }^{6}$ The distance between a non-equilibrium $w$ and $\bar{w}$ is defined, as in the proof of the theorem, as $\sum_{k=1}^{m}\left(1 / 2 \alpha_{k}\right)\left(w_{k}(t)-\bar{w}_{k}\right)^{2}$. It is common to set the adjustment speeds equal to 1 , in which case this definition coincides with standard Euclidean distance.
} 
detailed example involves just one time period, and therefore no switching back and forth between techniques can arise. To clarify the situation let us consider an example with just a single produced good, no choice of activities and hence no possibility of switching let alone reswitching, a single agent, and where nevertheless some factor prices can momentarily move away from their equilibrium values (or momentarily be stuck at 0 ) in a factor tâtonnement. Let the single activity use one unit of labor and one unit each of two material inputs to produce one unit of the economy's one output. Since there is only one output, the model exhibits an aggregate (Leontiev) production function. If $p$ is the price of output, $w_{1}$ is the wage, and $\left(w_{2}, w_{3}\right)$ are the material input prices, the zero-profit condition is $p=w_{1}+w_{2}+w_{3}$. As in Schefold's model, the single consumer may consume some of the initial stocks of the material inputs but supplies labor inelastically. If the labor endowment is 1 and the material input endowments are $(2,2)$, the consumer's budget constraint is

$$
p c+w_{2} x_{2}+w_{3} x_{3} \leq w_{1}+2 w_{2}+2 w_{3}
$$

where $\left(c, x_{2}, x_{3}\right)$ is the agent's consumption of output and material inputs. Suppose that at the prices $w_{1}=w_{2}=w_{3}=1$ and therefore $p=3$, the consumer's utility-maximization problem is solved at $c=x_{2}=x_{3}=1$; the economy is then in equilibrium. Next, let us announce the out-of-equilibrium factor prices $w_{1}=0, w_{2}=1, w_{3}=3$. Since then $p=4$, the consumer faces the budget constraint $4 c+x_{2}+3 x_{3} \leq 8$. Now suppose the consumer demands $\left(c, x_{2}, x_{3}\right)=\left(\frac{2}{7}, 6, \frac{2}{7}\right)$ at the new prices. Since this bundle is not affordable at prices $w_{1}=w_{2}=w_{3}=1, p=3$, there must be a utility function for the consumer that generates these demands (since these two observations of demand satisfy the weak axiom of revealed preference and hence, with just two observations, also the strong axiom). With demand for output equal to $\frac{2}{7}$, the demand for labor also equals $\frac{2}{7}$, strictly less than the supply of 1 . The wage (calculated in any numeraire) thus falls short of its equilibrium level and yet a factor tâtonnement would call for further reduction. Just as in Schefold's examples, however, the wage will increase later in the adjustment process. ${ }^{\text {? }}$

\footnotetext{
${ }^{7}$ Schefold considers an alternative price adjustment rule, in which announced prices for labor each period and initial-period stocks again generate minimum-cost prices for the consumption goods, and consumers again declare their consumption demands and factor supplies. But now consumption demand translates into factor demand as follows: after firms in period 1 produce enough to satisfy consumption demand in period 1, they invest any remaining resources into production for period 2 , which is then used to satisfy period 2 consumption demand, and so on.
} 


\section{COMPARATIVE STATICS WITH A SINGLE CONSUMER}

The comparative statics of single-agent economies are notably well behaved. As I mentioned in Mandler (2002b), if the consumer has a concave utility function, an increase in any factor's endowment decreases its marginal value. This conclusion holds even if capital fails to aggregate and even if reswitching is possible. Schefold nevertheless insists that changes in the factor endowments of his single-agent economy exhibit a capital theory paradox.

To recap, the equilibrium relative prices of Schefold's model are constant during the economy's initial periods and constant again (or nearly so) during the economy's terminal periods. At the beginning and end of the model, therefore, we may speak of 'the' interest rate $r$ on one-period loans. The economy starts out at $t=0$ with a high interest rate, say $r_{H}$, at which a certain $\alpha$ subset of activities is profit-maximizing. At some $t^{\prime}>0$, the economy's perperiod endowment of labor, constant up until this point, permanently shifts to a higher level. Schefold constrains the vector of gross outputs to be the same in every period $t \geq 0$, and therefore full usage of the larger labor supply requires that different activities be employed. So Schefold supposes there is a $\beta$ set of activities that requires more labor to produce the same output vector, and furthermore that when relative prices are constant these $\beta$ activities are profit-maximizing only when $r<r_{H}$ and thus the real wage is larger than it is with $r_{H}$. (Reswitching per se-where there is an even lower $r$ at which the $\alpha$ activities are again profit-maximizing when relative prices are constant - does not appear to be key to the story.) So the intertemporal equilibrium begins with a small labor endowment and low wages and ends up with a large labor endowment and high wages. For the economy to switch to the $\beta$ activities just when the larger labor endowment arrives at $t^{\prime}$, output and factor prices must prior to $t^{\prime}$ begin to deviate from the values that rule at the beginning of the equilibrium. The price and input usage paths must coexist with a constant path for aggregate outputs, which is achieved by

If the announced factor prices are inconsistent with equilibrium, a supply-demand discrepancy will show up in some labor or output market. For example, it may be impossible, no matter how resources up to period $t$ are invested, for production to meet period $t$ 's consumption demand. Schefold adjusts the wage at each period $t$ according to the difference between its demand and supply, but the rest of the adjustment rule is not well defined (even ignoring that more than one profit-maximizing activity can produce the same outputs). How should the auctioneer respond to a supply demand discrepancy in the demand for the capital inputs that appear after the initial period? Since these capital inputs are produced, their prices cannot be adjusted independently of the prices of the inputs used to produce them one period earlier. And when out of equilibrium, into which goods are surplus resources invested? 
assuming that at the specified price path the single consumer happens to demand exactly the consumption vector that is left over after the capital goods used are subtracted from output. So the relative price changes that precede $t^{\prime}$ are compatible with equilibrium due to a simultaneous shift in the consumer's marginal utilities that fortuitously keeps supply and demand for output aligned.

Schefold presents the simultaneous increases of labor supply and wages as a paradox and a capital theory paradox at that. Both prongs of this claim are hard to validate. Even the parables of neoclassical factor price theory assert only that an increase in a factor's endowment lowers its price when all else is equal. When multiple exogenous variables in a model change simultaneously, the theory claims only that an endowment increase lowers a factor's price relative to what the price would have been if the other exogenous variables were still to change but the factor endowment increase did not occur. The neoclassical position is thus a counterfactual or 'comparative statics' result about how the values of equilibrium variables differ in one equilibrium compared with another. Although it is awkward, one can embed a counterfactual in a single equilibrium by asking how an equilibrium changes through time if at one specific date some exogenous variable shifts but the remaining data of the economy stay constant. But in Schefold's equilibrium both the labor supply increases and the per-period utility functions shift (indeed the per-period utility function begins to shift before labor supply does). The conclusion that labor supply and wages both increase therefore does not violate any neoclassical claim that I am aware of. Firms adopt the $\beta$ activities, despite the fact that they are more labor-intensive and the higher wage, because the $\beta$ activities economize on the use of a suddenly more expensive capital input and instead intensively use a suddenly cheaper capital input. The change in capital input prices in turn are driven by the shifts in the consumer's utility function.

Schefold affirms that his equilibrium is obviously paradoxical — shouldn't this judgment remain in the eyes of the beholders? - but his main response to the above criticism is that a labor-market participant would not regard the time path of wages to be reasonable. Even if we grant that judgments of reasonableness matter, an observer of the labor market would see both an increase in labor supply and an increase in labor demand (in the partial equilibrium sense of the demand for labor that is determined by the stocks of capital inputs devoted to production). ${ }^{8}$ Assuming that simultaneous shifts

\footnotetext{
${ }^{8}$ There is a sequential indeterminacy problem in Schefold's model if wages and capital goods prices are set by markets in the period they are utilized (see Mandler, 1995, 2000a). But if capital inputs are not traded during the period they are utilized and wages are set a period in advance, or if labor supply varies with the wage, the problem disappears.
} 
of supply and demand are permissible, the labor market operates in an entirely routine way. It so happens that the shift in labor demand stems from changes in the prices of other inputs, which in turn are caused by changes in tastes.

In any event, capital theory paradoxes, which hinge on some inputs being produced, are irrelevant to these labor market dynamics. Suppose there is an aggregate production function that generates one good using labor and seed as inputs. If seed serves as a consumption good as well, then a decrease in agents' utility for seed would generate an increase in labor demand (at any combination of labor and seed prices satisfying the zero-profit condition, the amount of labor employed by the seed that is not to be consumed would be larger). If simultaneously with this utility shift, labor supply were to increase, then the labor market would behave just as paradoxically as Schefold's does.

Schefold's equilibrium as a whole, with a utility function that at some point begins to shift every period and agents who accurately predict a path of changing prices, may indeed seem implausible. The implausibility inheres in perfect foresight, however, particularly when exogenous variables follow a convoluted path or when multiple markets interact. For example, if agents anticipate future prices with complete accuracy, then changes in exogenous variables that occur in the distant future can lead to changes in current prices or quantities. But this species of implausibility should not be mistaken for capital theory implausibility. Indeed, one can readily construct pure exchange economies that better illustrate the problem. If in an intertemporal exchange economy, consumption at period 20 alters the marginal utility of some period 1 goods, then changes in period 20 endowments will change period 1's prices even when the period 1 data remain unaltered. In Schefold's model at least relative prices first deviate from their initially constant values at just the same time that the per-period utility function first shifts.

My guess would be that not a single proponent of general equilibrium theory holds that perfect foresight accurately describes agents' expectations. Perfect-foresight models are not designed to deliver descriptive accuracy. They are designed to illuminate other questions - e.g. what elements of an intertemporal economy help or hinder efficiency? - while putting aside inevitable errors in agents' expectations. It may well be that this abstraction undermines the value of any lessons drawn, but perfect foresight at least allows one to distinguish between the effects of erroneous expectations and other assumptions. For example, that a perfect-foresight equilibrium in the overlapping generations model can be Pareto suboptimal establishes that market clearing even under the best of circumstances need not lead to efficiency. A model with a more realistic view of expectations would introduce another source of inefficiency and therefore muddy this conclusion. 
Overshooting models of asset prices furnish a second example. Even when agents have perfect foresight, an interest rate reduction can lead a currency to overshoot - to drop temporarily below its new lower long-run equilibrium value. Foreign currency traders of course do not have perfect foresight, but a more accurate model of their expectations would obscure what overshooting models have to say, namely that the seemingly exaggerated swings of exchange rates need not stem from herd psychology and can persist no matter how perceptive traders become.

\section{ADJUSTMENT MECHANISMS WITH OUT-OF-EQUILIBRIUM TRADING}

The factor tâtonnements that Schefold and I consider suffer from two serious drawbacks. First, although a tâtonnement presumably must take place in the economy's initial time period, some of the factors whose prices need to equilibrate appear only later on; if futures markets for these factors do not exist, how would the tâtonnement operate? One possible if only partly satisfactory answer would be to suppose that the tâtonnement operates only in the current period and that agents calculate the equilibrium prices that rule in subsequent periods in their heads. Second, the factors demands that govern the tâtonnement are calculated on the assumption that agents are price-takers even when non-equilibrium prices are announced. But if prices are inconsistent with equilibrium then consumers by definition do not supply enough of some of factors to meet producer demand, and hence consumer demand for output could not be satisfied either. A tâtonnement must therefore be understood as a hypothetical device in which agents do not trade until markets equilibrate, not a model of how trading through time leads to equilibrium.

In the Garegnani (2000) model, disequilibrium is expressed only as a discrepancy between savings and investment in the initial period. The intention, I think, is to show that capital theory paradoxes can lead to a perversely shaped investment demand schedule and thus provide an independent source of instability. Savings is defined as the difference between the value of the economy's initial stocks of material goods and the value of the portion of the stocks that are consumed, whereas investment is the value of the portion of the stocks that are invested as capital inputs. These capital inputs and labor are then used to produce goods that appear in the model's second and final period. When a non-equilibrium interest rate is announced, initial-period goods markets do not clear. Instead Garegnani solves for prices in both periods, output levels for the second period, and initial-period demands that satisfy (1) the model's zero-profit conditions, (2) market clear- 
ing in both the labor market and the second-period goods markets, and finally (3) a restriction on the ratio of out-of-equilibrium demands for the initial-period goods. With these endogenously determined prices and quantities in hand, Garegnani calculates investment and savings and adjusts the interest rate according to the difference between them. Garegnani does not explain how consumers formulate their demands when the interest rate is set at a disequilibrium value, but the endogenously determined quantities might not satisfy the economy's feasibility constraints (if firms' investment demands outstrip saving, actual investment can be insufficient to produce secondperiod outputs). The model amounts to another example of hypothetical trading, not a theory of feasible disequilibrium trading. I therefore do not see why it is a better account of adjustment than a traditional tâtonnement, but it does at least place investment demand front and center.

Unfortunately Garegnani's present discussion leaves the difficulties I mentioned in Mandler (2002b) outstanding. Since goods markets in the initial period of his model do not clear, the prices of output in the initial period should change through time, as in a tâtonnement, according to the sign of excess demand. There is no reason why, after the adjustment in the interest rate that a investment-saving discrepancy induces, the new solutions to Garegnani's equations would accommodate these necessary responses in the initial-period prices.

I am also puzzled how disagreement can remain regarding the uniqueness of equilibrium in Garegnani's model when there is a single consumer. When saving equals investment in Garegnani's model, full intertemporal general equilibrium obtains. But in a single-agent general-equilibrium model with a single-valued demand function, there can be just one bundle that the agent can trade in any equilibrium. To see this, suppose the weak axiom holds and that $\bar{p}$ and $p^{\prime}$ are each equilibrium price vectors with $z(\bar{p}) \neq z\left(p^{\prime}\right)$. Since $y=z(\bar{p})$ is produced by profit-maximizing firms at prices $\bar{p}$ and $z\left(p^{\prime}\right)$ is in the production set, $\bar{p} \cdot z(\bar{p}) \geq \bar{p} \cdot z\left(p^{\prime}\right)$. Hence Walras' law implies $\bar{p} \cdot z\left(p^{\prime}\right) \leq 0$. Similarly, we have $p^{\prime} \cdot z(\bar{p}) \leq 0$. But the weak axiom and the first inequality imply $p^{\prime} \cdot z(\bar{p})>0$, a contradiction. This argument applies both to economies with intermediate goods and to intertemporal models. In the single-agent case, therefore, Garegnani's investment and savings schedules cannot be as Garegnani draws them. ${ }^{9}$

\footnotetext{
${ }^{9}$ If the single agent's utility function is differentiable then the relative prices of consumption goods are uniquely determined as well. With an activity analysis description of technology, the equilibrium prices of inelastically supplied factors can be indeterminate (Mandler, 1995) even when there is a single agent but the set of equilibrium prices will not be discrete, it is a convex set.
} 
To pave a way forward, let me lay out a model that would allow disequilibrium to appear only as a difference between savings and investment and where disequilibrium trading is feasible. I will stay as close to Garegnani's model as possible and assume there are just two periods (today and tomorrow) with an existing stock of goods today that is either consumed or invested as capital in the production of tomorrow's output. My root confusion about Garegnani's model concerns the savings-investment market: although Garegnani points to a market where savers and investors exchange quantities of value, disequilibrium nevertheless appears only as separate discrepancies between the savings and investment of particular goods in today's product markets. Let us suppose instead that savers and investors meet at a loan or asset market. Some of the borrowers are firms, the only agents who purchase capital goods for production of tomorrow's output. At a loan-issuing bank, borrowers would pay and lenders would earn an interest rate between the two periods, calculated in terms of a bundle of goods that serves as numeraire. In the asset-market interpretation, agents would buy and sell promises to deliver a specified quantity of the numeraire bundle in the next period.

If the interest rate $\bar{r}$ at the bank is consistent with a full intertemporal equilibrium, then suppose that the equilibrium prices for today's goods rule in the concurrent goods markets and that agents unanimously anticipate that the accompanying equilibrium prices for tomorrow's goods will rule tomorrow. If, on the other hand, the bank announces a non-equilibrium interest rate $r$ then the demand and supply for loans cannot match (assuming today's markets clear and tomorrow's prices are correctly anticipated): one side of the market will have to be rationed. If the borrowers are the rationed party, suppose that each potential borrower faces a common ceiling on the volume of debt he or she may incur. (But let each borrowing firm purchase any of the capital goods and produce any good for the second period, ensuring that capital goods are purchased so that the shadow rate of return that a marginal increase in borrowing earns is the same across sectors.) If lenders are the rationed party, suppose that each lender then faces a common ceiling on the volume of loans he or she may contract. We assume that at most one side of the market is rationed at any $r$.

Given $r$, the model simultaneously sets (1) a ceiling constraint on either borrowers or lenders, (2) today's and tomorrow's prices, (3) firms' borrowing decisions, purchases of capital goods and production decisions, and (4) consumer borrowing-lending decisions and consumption purchases such that (a) each consumer's consumption purchases and borrowing-lending decision are utility-maximizing given prices and the ceiling constraint, (b) each firm's borrowing decision is profit-maximizing given prices and the ceiling constraint, (c) the sum of consumption demand for today's output 
and firms' capital-goods demand equals today's initial endowment, (d) consumption demand for tomorrow's output equals firms' supply tomorrow, and (e) the magnitude of the ceiling constraint is minimized. The last requirement ensures that rationing does no more than reconcile the savingsinvestment discrepancy caused by a non-equilibrium $r$.

For $r$ near $\bar{r}$, the above equilibrium conditions should determine locally unique values for the ceiling constraint, prices and quantity decisions, and these solutions should vary continuously as a function of $r$ near $\bar{r}$. The simplest way to imagine how this economy would function is to invoke rational expectations; agents accurately foresee tomorrow's prices given the announced interest rate and today's prices and purchases of capital inputs. Rational expectations, as I explained in the previous section, is unrealistic but a modeling advantage; to press the case that reswitching can lead to instability, one should exclude any other possible cause.

Dynamic adjustment would proceed as follows: if at some $r$, borrowers but not lenders are rationed, then the change in $r$ would be positive, while if lenders are rationed but not borrowers, then the change in $r$ would be negative. Stability obtains if any path for $r$ defined by this process converges to an equilibrium $r$ and the ceiling constraint converges to 0 . The more modest goal of local stability obtains if small deviations of $r$ from $\bar{r}$ are selfcorrecting, e.g. when $r$ is slightly larger than $\bar{r}$ and lenders are rationed, then $r$ would approach $\bar{r}$ from above and the size of lenders' ceiling constraint would converge to 0 . I do not know when the above adjustment rule is stable for a single-consumer economy, but I would be surprised if the answer hinged on capital aggregation. But at least the present model allows one to address Garegnani's question: can the failure of capital to aggregate lead a pure savings-investment adjustment process to diverge from equilibrium?

\section{CONVERGENCE TO CONSTANT RELATIVE PRICES}

Most of the remaining disputes concern whether relative prices will ultimately stabilize through time. Garegnani argues that neoclassical models cannot achieve relative price stability unless they assume that capital aggregates, and theories that fail to make this connection are inadequate. For instance, the sequential indeterminacy criticisms of Mandler (1995, 2002a) are misguided because that they do not encompass the larger neoclassical indeterminacy problem that the need for aggregate capital exposes.

As I pointed out in Mandler (2002b), however, there are neoclassical models of intertemporal equilibrium, such as turnpike models, that converge forward to a long-run equilibrium at which relative prices are constant 
through time. The assumptions necessary for a turnpike result are strong; the preference and endowment primitives must stay constant through time and a wider array of convergence results are attainable if the consumer side of the model behaves as a single agent (McKenzie, 1986). ${ }^{10}$ Once again, the remaining stone to look under is a link between the multiplicity of agents and the multiplicity of capital goods; perhaps with many agents convergence obtains more readily when capital aggregates.

The convergence of relative prices in neoclassical models seems to be too slow for Sraffian tastes; it obtains only on the same time frame as capital accumulation comes to a stop or a steady state is reached. Let me repeat my guess from Mandler (2002b) that calibrated general-equilibrium models, even if they have multiple capital goods, would nevertheless turn out to have paths of relative prices that approximately converge with great speed. This speculation may turn out to be incorrect, but at least there is a neoclassical theory of how capital and other quantities evolve through time. In contrast, although Sraffians stipulate that models should exhibit relative prices that converge, they do not explain how or why this property should hold. Moreover the very forces that can block relative price convergence in a neoclassical model will pose obstacles to relative price convergence in any Sraffian model of intertemporal equilibrium as well. Even if Sraffians exempt wages from the laws of supply and demand, they must concede that natural resources are priced by markets. Some resources moreover are becoming progressively more scarce or harder to extract, and arbitrageurs can be expected to anticipate the resulting rise in their relative prices, which will bring forward the price effect of future resource scarcity. Hence just as in neoclassical theory convergence to literally constant relative prices will typically be impossible. It could turn out that approximate convergence does obtain and in relatively short order, just as it might in neoclassical models. But the convergence question is just as pressing in a Sraffian world as it is in a neoclassical one, or perhaps more pressing since Sraffian theory risks falling prey to its own critique.

\footnotetext{
${ }^{10}$ In lieu of a response to Schefold (2005b), let me point out that the regularity condition in McKenzie (1986), which is related to conditions that in Schefold's view do away the problems of capital theory, is a result, not an assumption: regularity follows from local stability (under certain conditions) not vice versa. Convergence of relative prices in a single-agent economy therefore does not presuppose that capital theory problems are ruled out of court; rather it eliminates those problems.
} 


\section{APPENDIX}

Proof of Theorem: Let $\bar{w}$ denote an equilibrium $w$, and define the distance between $w(t)$ and $\bar{w}$ as $V(t)=\sum_{k=1}^{m} \frac{1}{2 \alpha_{k}}\left(w_{k}(t)-\bar{w}_{k}\right)^{2}$. If $V$ is non-increasing, if $\dot{V}(t)<0$ when $V$ is differentiable at $t$ and $w(t)$ is not an equilibrium $w$, and if $\dot{V}(t)=0$ when $w(t)=\bar{w}$, then Aubin and Cellina (1984, Theorem 6.5.5) implies that $w(t)$ converges to an equilibrium.

Establishing these properties for $V$ repeats the textbook argument for tâtonnement stability once we show that $\xi(w)=\left\{z_{f}(w)\right\}-Y_{f}(w)$ satisfies the condition 'if $w$ is not an equilibrium and $\xi \in \xi(w)$, then $\bar{w} \cdot \xi>0$.'

Given some non-equilibrium $w$, the fact that $\bar{w}$ is an equilibrium implies $w \cdot\left(z_{f}(\bar{w})-\bar{y}_{f}\right)=0$ for some $\bar{y}_{f} \in Y_{f}(\bar{w})$. Suppose, contrary to the condition, that $\bar{w} \cdot\left(z_{f}(w)-y_{f}\right) \leq 0$ for some $y_{f} \in Y_{f}(w)$. Since $\left(z_{c}(w), y_{f}\right)$ is an element of the production set $Y=\{y: y=A x$ for some $x \geq 0\},\left(p_{c}(\bar{w}), \bar{w}\right) \cdot\left(z_{c}(w), y_{f}\right) \leq 0$. Hence $\left(p_{c}(\bar{w}), \bar{w}\right) \cdot\left(z_{c}(w), z_{f}(w)\right) \leq 0$. Similarly, since $\left(z_{c}(\bar{w}), \bar{y}_{f}\right) \in Y,\left(p_{c}(w)\right.$, $w) \cdot\left(z_{c}(\bar{w}), \bar{y}_{f}\right) \leq 0$, and so $w \cdot\left(z_{f}(\bar{w})-\bar{y}_{f}\right)=0$ implies $\left(p_{c}(w), w\right) \cdot\left(z_{c}(\bar{w})\right.$, $\left.z_{f}(\bar{w})\right) \leq 0$. But since $w$ is not an equilibrium, $\left(z_{c}(w), z_{f}(w)\right) \neq\left(z_{c}(\bar{w}), z_{f}(\bar{w})\right)$, violating the weak axiom. Thus $\bar{w} \cdot\left(z_{f}(w)-y_{f}\right)>0$ for any $y_{f} \in Y_{f}(w)$, as desired.

For the amended adjustment rule that maintains $w(t) \geq 0$, observe that for all $w^{\prime} \geq 0$ and all $\hat{\xi} \in \hat{\xi}\left(w^{\prime}\right)$, there is a $\xi \in \xi\left(w^{\prime}\right)$ such that $\hat{\xi} \geq \xi$. (See footnote 3 for the definition of $\hat{\xi}$.) Since for any non-equilibrium $w \geq 0$ and $\xi \in \xi(w), \bar{w} \cdot \xi>0$, it is also the case that $\bar{w} \cdot \hat{\xi}>0$ for any non-equilibrium $w$ and $\hat{\xi} \in \hat{\xi}(w)$.

Returning to $V$, we have when $V$ is differentiable at $t, \dot{V}(t)=\sum_{k=1}^{m}\left(w_{k}(t)-\bar{w}_{k}\right) \xi_{k}$ for some $\xi \in \xi(w(t))$. Walras' law and the zero-profit condition $p_{c}(w(t)) \cdot z_{c}(w(t))+w(t) \cdot y_{f}=0$ for $y_{f} \in Y_{f}(w(t))$ imply $w(t) \cdot \xi=0$ for $\xi \in \xi(w(t))$. Hence $\dot{V}(t)=-\bar{w} \cdot \xi$, which we have shown is strictly negative if $w(t)$ is not an equilibrium. Since $V$ is differentiable almost everywhere, $V$ is nonincreasing. Since $\bar{w} \cdot \xi=0$ for $\xi \in \xi(\bar{w}), \dot{V}(t)=0$ when $w(t)=\bar{w}$.

\section{REFERENCES}

Arrow, K., Block, H., Hurwicz, L. (1959): 'On the stability of the competitive equilibrium, II', Econometrica, 27, pp. 82-109.

Arrow, K., Starrett, D. (1973): 'Cost-theoretical and demand-theoretical approaches to the theory of price determination', in Hicks, J. R., Weber, W. (eds): Carl Menger and the Austrian School of Economics, Clarendon Press, Oxford.

C) Blackwell Publishing Ltd 2005 
Aubin, J., Cellina, A. (1984): Differential Inclusions, Springer-Verlag, Berlin.

Champsaur, P., Dreze, J., Henry, C. (1977): 'Stability theorems with economic applications', Econometrica, 45, pp. 273-94.

Garegnani, P. (2000): 'Savings, investment, and capital in a system of general intertemporal equilibrium', in Kurz, H. (ed.): Critical Essays on Piero Sraffa's Legacy in Economics, Cambridge University Press, Cambridge.

Garegnani, P. (2005): 'Capital and intertemporal equilibria: a reply to Mandler', Metroeconomica, 56 (4), pp. 411-37.

Mandler, M. (1995): 'Sequential indeterminacy in production economies', Journal of Economic Theory, 66, pp. 406-36.

Mandler, M. (1999): Dilemmas in Economic Theory: Persisting Foundational Problems of Microeconomics, Oxford University Press, New York.

Mandler, M. (2002a): 'The sequential indeterminacy problem', in Hahn, F., Petri, F. (eds): General Equilibrium: Problems and Prospects, Routledge, London.

Mandler, M. (2002b): 'Classical and neoclassical indeterminacy in one-shot versus ongoing equilibria', Metroeconomica, 53, pp. 203-22.

McKenzie, L. (1986): 'Optimal economic growth, turnpike theorems and comparative dynamics', in Arrow, K., Intriligator, M. (eds): Handbook of Mathematical Economics, vol. 3, North-Holland, Amsterdam.

Schefold, B. (2000): 'Paradoxes of capital and counter-intuitive changes of distribution in an intertemporal equilibrium model', in Kurz, H. (ed.): Critical Essays on Piero Sraffa's Legacy in Economics, Cambridge University Press, Cambridge.

Schefold, B. (2005a): 'Reswitching as a cause of instability of intertemporal equilibrium', Metroeconomica, 56 (4), pp. 438-76.

Schefold, B. (2005b): 'Zero wages—no problem? A reply to Mandler', Metroeconomica, 56 (4), pp. $503-13$.

Department of Economics

Royal Holloway College

University of London

Egham, Surrey TW20 0EX

UK

E-mail: m.mandler@rhul.ac.uk 